\title{
1 Morc1 knockout evokes a depression-like phenotype in mice
}

Schmidt, M. ${ }^{\mathrm{a}}$, Brandwein, C. ${ }^{\mathrm{a}}$, Luoni, A. ${ }^{\mathrm{b}}$, Sandrini, P. ${ }^{\mathrm{b}}$, Calzoni, T. ${ }^{\mathrm{b}}$, Deuschle, M. ${ }^{\mathrm{a}}$, Cirulli, F. ${ }^{\mathrm{c}}$, Riva, M. A. ${ }^{\mathrm{b}}$, Gass, P. ${ }^{\mathrm{a}}$

${ }^{a}$ Central Institute of Mental Health Mannheim (ZI), Medical Faculty of Mannheim, University of Heidelberg, J5, D-68159 Mannheim, Germany; michaela.schmidt@zi-mannheim.de, christiane.brandwein@zi-mannheim.de, michael.deuschle@zi-mannheim.de, peter.gass@,zimannheim.de

${ }^{\mathrm{b}}$ Department of Pharmacological and Biomolecular Sciences, University of Milan, Via Balzaretti, 9, I-20133 Milan, Italy; alessia.luoni@unimi.it, m.riva@unimi.it, paolo.sandrini@studenti.unimi.it, teresa.calzoni@studenti.unimi.it

${ }^{c}$ Behavioural Neuroscience Section, Department of Cell Biology and Neurosciences, Istituto Superiore di Sanità, Viale Regina Elena 299, I-00161 Rome, Italy; francesca.cirulli@,iss.it

Address for correspondence and reprint requests:

Michaela Schmidt, Dipl-Psych, MD

Central Institute of Mental Health Mannheim (ZI)

Medical Faculty of Mannheim

University of Heidelberg

J 5

D-68159 Mannheim, Germany

Phone: +49621 3832603

Fax: $\quad+496213832602$

e-mail:michaela.schmidt@zi-mannheim.de 


\section{Abstract}

Morcl gene has recently been identified by a DNA methylation and genome-wide association study as a candidate gene for major depressive disorder related to early life stress in rodents, primates and humans. So far, no transgenic animal model has been established to validate these findings on a behavioral level. In the present study, we examined the effects of a Morcl loss of function mutation in female $\mathrm{C} 57 \mathrm{BL} / 6 \mathrm{~N}$ mice on behavioral correlates of mood disorders like the Forced Swim Test, the Learned Helplessness Paradigm, O-Maze and DarkLight-Box. We could show that $\mathrm{Morcl}^{-/}$mice display increased depressive-like behavior whereas no behavioral abnormalities regarding locomotor activity or anxiety-like behavior were detectable. The baseline CORT plasma levels did not differ significantly between $\mathrm{Morcl}^{-/}$mice and their wildtype littermates, yet - surprisingly - total BDNF mRNA-levels in the hippocampus were up-regulated in $\mathrm{MorCl}^{-/-}$animals. Although further work would be clarifying, $\mathrm{Morcl}^{-/-}$mice seem to be a promising epigenetically validated mouse model for depression associated with early life stress.

Keywords: depression; Morc1; transgenic mice; early life stress; epigenetics; BDNF. 82 


\section{Introduction}

Clinical studies show that early life stress has profound and persistent effects on brain functions and is one of the major risk factors for developing a depressive disorder later in life [1], [2], [3]. The fundamental role of epigenetics mediating this process became clear in the groundbreaking animal study of Weaver et al. [4]: life-long epigenetic modifications of the glucocorticoid receptor gene in the rat hippocampus induced by early life stress were followed by a stable enhanced HPA response to stress. In the meantime, several studies identified effects of early life stress on DNA methylation for further genes in rodents [5], [6], [7], [8], [9]. For some of these genes, like BDNF, the serotonin transporter and the glucocorticoid receptor, altered DNA methylation was also revealed in humans after experiencing early life stress [10], [11], [12]. All of the above-cited studies focused on a candidate gene approach. Transgenic mice models with altered expression of the examined genes only partially show a consistent depressive-like phenotype [13], [14], [15], [16], [17]. Two more recent studies used a genome-wide methylation analysis and reported a wide range of epigenetic alterations as a result of early life stress [18], [19], but none of them led to a behaviorally validated mouse model for depression.

In a novel systematic translational genome-wide epigenetic approach, we recently succeeded in detecting an epigenetic marker of early life stress that is present in blood cell progenitors at birth in humans and monkeys, and also detectable in the prefrontal cortex of adult rats: Microrchidia (MORC) 1 - alias MORC family CW-type zinc finger 1 [20]. Moreover, we were able to verify an association between Morcl and major depressive disorder in a gene-set based analysis of an already available genome-wide association study [21].

MORC was first described in mammals by Watson et al. [22], who found that it is mainly expressed in male germ cells where it regulates mammalian germ cell development and meiosis. Male Morcl $^{-/-}$mice are infertile due to a disrupted spermatogenesis, whereas male 
$110 \mathrm{Morcl}^{+/-}$and female $\mathrm{Morcl}^{-/-}$mice do not show deficits in their reproductive system, Morcl

111 knockout mice were seen exclusively as a model for male fertility defects. The human MORC

112 protein consists of 984 amino acids and is $66 \%$ identical to the mouse MORC. Mutations in

113 humans might also cause male infertility and be involved in testicular germ cell tumors [23].

114 More recently Pastor et al. [24] reported that the male infertility in Morcl mutant mice is

115 caused by defects of DNA methylation of specific classes of transposons, resulting in failed

116 transposon silencing at these sites. Further analysis revealed that the MORC family is not only

117 decisive for male reproduction, but is also involved in the pathophysiology of numerous

118 forms of cancer: Morcl e.g. is frequently expressed in multiple myeloma [25] and mutated in

119 estrogen receptor-positive lobular breast cancer [26]. Additionally, Morcl has been related to

120 diabetes traits in a genome-wide complex trait analysis [27], which could play a role in the

121 association of major depressive disorder with type 2 diabetes mellitus. In plants, Morcl

122 influences immunological processes by different gene silencing mechanisms and

123 heterochromatin condensation [28], [29], [30]. Recent evidence suggests that Morcl plays a

124 more general biological role as part of a highly conserved nuclear protein superfamily that

125 serves as epigenetic regulators in diverse nuclear processes that are not yet fully understood

126 [31], [32], [33]. Hence Morc1 appears to be primarily involved in gene silencing and changes

127 of the chromatin structure [34], [35]. We were the first to report a different methylation of

128 Morcl in brain tissue - the prefrontal cortex of adult rats - and thus strongly support the

129 hypothesis of an epigenetic influence of this gene in the brain [20].

131 Animal models are still valuable tools in preclinical research, yet no rodent model of Morcl

132 regarding depressive-like behavior has been established. Thus, in the present study we aimed

133 to implement a transgenic mouse model to validate the role of Morcl expression in affective

134 disorders. For this purpose we used $\operatorname{Morc}^{\mathrm{Tg}(\mathrm{Tyr}) 1 \mathrm{Az} / \mathrm{J}}$ mice, in which exons 2-4 of Morcl gene

135 on chromosome 16 had been deleted with the help of a transgenic insert [36]. We 
136 characterized $\mathrm{MORC}^{\mathrm{Tg}(\mathrm{Tyr}) 1 \mathrm{Az} / \mathrm{J}}$ mice behaviorally in a test battery for locomotion and

137 exploratory, anxiety-like and despair behavior. Plasma corticosterone levels were analyzed as

138 a possible indicator of a depression-like HPA-system dysfunction. Furthermore, we

139 determined total BDNF mRNA-levels known to be decreased in hippocampus in depressive

140 patients and animal models of depression [37], [38], [39] as well as in closely connected and

141 presumably affected structures, such as prefrontal cortex and amygdala [40], [41]. Due to

142 difficult breeding and an increased mortality of male $\mathrm{Morcl}^{-/}$mice, we only used female

143 animals for our experiments, which is also the sex more predisposed to develop depression in

144 humans.

145 


\section{Materials and Methods}

\subsection{Animals}

$\operatorname{Morc}^{\mathrm{Tg}(\mathrm{Tyr}) 1 \mathrm{Az} / \mathrm{J}}$ mice had been generated by introducing a transgenic construct containing a tyrosinase gene under the control of an RNA polymerase II 1 promoter into FVB/N fertilized mouse eggs. Sequences adjacent to the transgenic insert are disrupted resulting in the deletion of Morcl exons 2-4 [36]. Heterozygous $\mathrm{Morcl}^{+-}$on the original FVB/N background were purchased from the Jackson Labs (Bar Harbour, Maine, USA) and crossed with C57BL/6N (Charles River, Sulzfeld, Germany) mice to obtain an F1 generation. Heterozygous F1 offspring were then inter-crossed to generate an F2 generation, which was used for behavioral and molecular analyses. Male $\mathrm{MorCl}^{-/}$mice were infertile and had smaller testes than wildtypes, whereas male $\mathrm{Morcl}^{+/-}$mice and female $\mathrm{Morcl}^{-/-}$mice showed no reproductive deficits. Animals were genotyped by PCR as recommended by the Jackson Labs (Bar Harbour, Maine, USA). Female Morcl $^{-/-}$mice and their wild-type littermates were housed individually 2 weeks before the first behavioural test started in macrolon type II cages with nesting material under a reversed day-night cycle (lights on from 19.00-07:00 hrs with 12h dark and 12-h light phase) and supplied with food and water ad libitum. All procedures complied with the regulations covering animal experimentation within the EU (European Communities Council Directive 2010/63/EU). They were conducted in accordance with the institutions' animal care and use guidelines and approved by the national and local authorities (Regierungspräsidium Karlsruhe).

\subsection{Behavioral tests}

At the age of 3, 5 and 6 months, 11 female $\mathrm{Morcl}^{-/-}$mice and 12 of their wild-type littermates were tested behaviorally in the dark phase, i.e., in the animals' active phase. Mice were acclimatized to the experimental room for at least 30 minutes prior to each test and tested by an investigator, who was blinded regarding their genotype. The order of the tests followed 
earlier recommendations ranking the tests from least stressful to more stressful. Mice were sacrificed 2-3 weeks after the last experiment at an age of $21-25$ weeks.

\subsubsection{Novel Cage Test}

Explorative behaviour was measured by counting the number of rearings within the first 5 minutes after placing the animal into a fresh standard type II macrolon cage as described earlier [42].

\subsubsection{Open Field Test}

To evaluate locomotor and exploratory behavior, mice were individually placed into an open arena measuring 50x50 $\mathrm{cm}^{2}$ under dimmed light conditions (25 Lux). Activity monitoring was conducted 15 min via a Video camera (Sony CCD IRIS). The resulting data were analyzed using the image processing system EthoVison 1.96 (Noldus Information Technology, Wageningen, the Netherlands) as described earlier [43].

\subsubsection{Dark-Light-Box}

Anxiety-related behavior was tested in the Dark-Light Box consisting of two plastic chambers connected by a small tunnel. Mice were placed into the dark chamber, which was covered by a lid and measured $20 \times 15 \mathrm{~cm}^{2}$. Latency to first exit, number of exits and total time in the aversive light compartment (30x15 $\mathrm{cm}^{2}$, illuminated with $600 \mathrm{Lux}$ ) was recorded for $5 \mathrm{~min}$ as described earlier [44].

\subsubsection{O-Maze}

The Elevated Zero-Maze analyzes anxiety-related behavior by assessing avoidance of the aversive unsheltered compartment of the arena. A grey plastic annular runway (width $6 \mathrm{~cm}$, outer diameter $46 \mathrm{~cm}, 50 \mathrm{~cm}$ above ground level, illuminated with 25 Lux) was covered with black cardboard paper to prevent animals slipping off the maze. Two opposing sectors were protected by inner and outer walls with a height of $10 \mathrm{~cm}$. Animals were placed in one of the 
protected sectors and latency to first exit, number of exits and total time spent in the open compartments was measured for 5 minutes as described earlier [45].

210

\subsubsection{Forced Swim Test}

The Forced Swim Test was applied to measure depressive-like behavior. For this purpose mice were placed into a glass cylinder $(23 \mathrm{~cm}$ height, $13 \mathrm{~cm}$ diameter $)$ filled with water $\left(22^{\circ} \mathrm{C}\right)$ up to a height of $8 \mathrm{~cm}$. Within a period of 6 min the onset and the percentage of floating was determined as described earlier [46]. 24 hours later the animals were tested again under the same conditions as before.

\subsubsection{Hot Plate Test}

To exclude altered pain sensitivity as a confounding factor for Learned Helplessness, the Hotplate Test (ATLab, Vendargues, France) was applied. Temperature was set at $53{ }^{\circ} \mathrm{C}$ $\left( \pm 0.3{ }^{\circ} \mathrm{C}\right)$ and a 45 s cut-off was determined to prevent injury. Latency to first reaction, i.e. licking hind paws or jumping, was assessed as described earlier [47].

\subsubsection{Learned Helplessness}

In the Learned Helplessness Paradigm mice were placed in a transparent plexiglas shock chamber $\left(18 \times 18 \times 30 \mathrm{~cm}^{3}\right)$ with a stainless steel grid floor (Coulborn Instruments, Düsseldorf, Germany) through which they received 360 unpredictable and unavoidable footshocks $(0.150 \mathrm{~mA})$ on 2 consecutive days. The footshocks applied varied regarding shock-duration (1-3s) and interval-episodes (1-15s) and lasted approximately $52 \mathrm{~min}$ in total. 24 hours after the second shock procedure, learned helplessness was assessed by testing shuttle box performance (Graphic State Notation, Coulborn Instruments, Düsseldorf, Germany) as described earlier [48]. Spontaneous initial shuttles from one compartment to the other were counted during the first $2 \mathrm{~min}$. Performance during 30 shuttle escape trials each starting with a 
236 light stimulus of $5 \mathrm{~s}$, announcing a subsequent footshock (intensity $0.15 \mathrm{~mA}$ ) of maximum $10 \mathrm{~s}$ 237 duration was analyzed. Inter-trial interval was 30 s and total testing time about $20 \mathrm{~min}$.

\subsection{CORT levels}

All animals were sacrificed at the age of 21-25 weeks by decapitation between 8.00 and 11.00

241 hrs in the morning, and trunk blood was collected within 30s after the animal's removal from 242 the cage. Baseline plasma corticosterone levels - without applying any acute stress or 243 intervention before taking the samples - were determined using commercially available 244 radioimmunoassay kits (ICN Biomedicals, Eschwege, Germany) as described earlier [49].

\subsection{RNA Preparation and Gene Expression Analysis by Quantitative Real-Time PCR}

247 After decapitation of the animals, the brains were immediately extracted from the skull. The hippocampus, prefrontal cortex and amygdala were rapidly dissected from the whole brain,

249 frozen on dry ice and stored for later analyses.

250 Total RNA was isolated by single step of guanidinium isothiocyanate/phenol extraction using 251 PureZol RNA isolation reagent (Bio-Rad Laboratories) according to manufacturer's 252 instructions and quantified by spectrophotometric analysis. Following total RNA extraction, 253 the samples were processed for real-time PCR (RT-PCR) to assess total BDNF mRNA levels. 254 An aliquot of each sample was treated with DNase to avoid DNA contamination. RNA was 255 analyzed by TaqMan qRTPCR instrument (CFX384 real time system; Bio-Rad Laboratories) 256 using the iScriptTM one-step RT-PCR kit for probes (Bio-Rad Laboratories). Samples were 257 run in 384 well formats in triplicate as multiplexed reactions with a normalizing internal 258 control (36B4). Primers and probes sequences of total BDNF (forward primer: 259 AAGTCTGCATTACATTCCTCGA, reverse primer: 260 GTTTTCTGAAAGAGGGACAGTTTAT and probe: TGTGGTTTGTTGCCGTTGCCAAG) 261 and 36B4 (forward primer: AGATGCAGCAGATCCGCAT, reverse primer: 
262 GTTCTTGCCCATCAGCACC and probe: CGCTCCGAGGGAAGGCCG) were purchased 263 from Eurofins Genomics (Vimodrone, Italy), while probe and primer sequences for Morc1 264 (Assay ID: Mm00501711_m1) were purchased from Life Technologies (Monza, Italy) and 265 are available on request.

\subsection{Statistical analyses}

268 Intergroup comparisons were calculated by one-sided t-tests assuming that knockout-mice 269 display higher levels of depressive and anxiety-like behavior as well as higher CORT-levels, 270 less body weight, less locomotor and exploratory behavior and decreased total BDNF mRNA271 levels in hippocampus, prefrontal cortex and amygdala than wild-types. A one-way repeated 272 measurements ANOVA was used to analyze the open field test. Calculations regarding 273 mRNA levels were run with fold change values. The correlation between Learned 274 Helplessness Escape Latency and Failures was analyzed applying spearman rho correlation. A 275 p-value $\leq 0.05$ was seen as the level of statistical significance in all tests. The statistical 276 analyses were performed using the SPSS 21.0 software package for Windows. 


\subsection{Morc1 knockout mice display regular locomotor and exploratory behavior}

$280 \mathrm{Morcl}^{-/}$mice showed normal vertical locomotor activity (rearing) in the Novel Cage Test $281(\mathrm{~T}(21)=0.874 ; \mathrm{p}=0.196$; data not shown). The horizontal locomotor activity and exploratory 282 behavior as measured by the Open Field Test also did not differ significantly from control 283 animals: e.g. the total distance moved by $\mathrm{Morcl}^{-/}$mice was similar to those of the control 284 group (time*genotype: $F_{1,21}=1.125, p=0.301$; between subject-factor genotype $F_{1,21}=0.032$; $285 \mathrm{p}=0.859)$. Both genotypes moved significantly less in the second half of the test, showing that habituation had taken place as expected (Time: $F_{1,21}=8.792 ; p=0.007$; data not shown).

\subsection{Morcl knockout mice show unaltered anxiety-related behavior}

Morcl $^{-/}$mice did not display increased anxiety-like behavior as monitored in the Dark-Light

Box (latency: $\mathrm{T}(21)=1.023 ; \mathrm{p}=0.159$; end exploration: $\mathrm{T}(14.011)=0.914 ; \mathrm{p}=0.188$; exits: $\mathrm{T}(21)=-1.289 ; \mathrm{p}=0.106$; light time: $\mathrm{T}(21)=-0.074 ; \mathrm{p}=0.471$; data not shown). In the Elevated their littermate controls $(\mathrm{T}(21)=0.314 ; \mathrm{p}=0.3785$; data not shown). They also did not exit $(\mathrm{T}(21)=-0.128 ; \mathrm{p}=0.4495$; data not shown) or fully cross $(\mathrm{T}(21)=0.095 ; \mathrm{p}=0.4625$; data not shown) the maze less than controls and spent about the same amount of time in the open arms of the maze $(T(21)=-0.862 ; p=0.199 ;$ data not shown $)$.

\subsection{Morcl knockout mice demonstrate increased depressive-like behavior}

Depressive-like behavior as measured by the Forced Swim Test showed that $\mathrm{Morcl}^{-/}$mice 300 display a significant lower latency to float $(\mathrm{T}(21)=2.346 ; \mathrm{P}=0.015)$ on day 1 than wild-types 301 (s. Fig 1A). Additionally, on day 1 immobility times were increased in $\mathrm{Morcl}^{-/}$mice, which resulted in a statistical tendency from minute 4 to 6 of the test (minute 0 to 2 : T18.051=-0.819; 
$\mathrm{p}=0.216$; minute 2 to $4: \mathrm{T} 21=-0,567 ; \mathrm{p}=0.289 ;$ minute 4 to $6: \mathrm{T} 21=-1.343 ; \mathrm{p}=0.097$; . figure 304 1B).

30524 hours later (on day 2), the difference in the latency to start floating was not detectable any 306 more (T21=0.113; p=0.456; s. fig. 1C.) Furthermore, Morc $1^{-/}$mice showed a significant 307 increase in immobility on day 2 from minute $2-4$ compared to wild-types $(\mathrm{T}(21)=-2.009$; $308 \mathrm{p}=0.029)$ and a statistical tendency also from minute $4-6(\mathrm{~T} 21=-1.431 ; \mathrm{p}=0.084)$ as depicted 309 in fig. 1D. From minute 0 to 2 there was no significant difference in immobility time between 310 the two groups $(\mathrm{T} 21=-0.508 ; \mathrm{p}=0.308)$.

312 In the Learned Helplessness Paradigm of depression, $\mathrm{MorCl}^{-/}$mice displayed significantly 313 more failures to escape in comparison to littermate controls $(\mathrm{T}(12.573)=-1.844 ; \mathrm{p}=0.045)(\mathrm{s}$. 314 Fig 2A). As a tendency, Morcl $^{-/}$mice had a higher latency to escape than controls (T $315(16.093)=-1.539 ; \mathrm{p}=0.072)$ as shown in fig. 2B. A clear correlation between escape latency 316 and number of failures with the $\mathrm{Morcl}^{-/}$mice showing the highest values (spearman 317 rho $=0.961, \mathrm{p}<0.000)$ is depicted in fig. 2 C.

3.4 Morc1 knockout mice reveal regular CORT levels, but increased total BDNF in hippocampus

$321 \mathrm{Morcl}^{-/}$mice showed similar plasma corticosterone levels as their control littermates $322(\mathrm{~T}(21)=-0.941 ; \mathrm{p}=0.1785 ; \mathrm{s}$. fig. 3A). In the hippocampus however, total BDNF mRNA-levels 323 of $\mathrm{Morcl}^{-/}$mice were significantly increased compared to those of wild-types $(\mathrm{T}(21)=-3.538$; $324 \mathrm{p}=0.001$; s. Fig. 3B). As a tendency, the total BDNF mRNA-levels in the prefrontal cortex $325(\mathrm{~T}(14.968)=1.428 ; \mathrm{p}=0.087$; data not shown $)$ and in the amygdala $(\mathrm{T}(18)=1,337 ; \mathrm{p}=0.099$; 326 data not shown) were down-regulated. 
327 As expected, Morcl mRNA was not expressed in Morcl $^{-/-}$mice, whereas we found its full 328 mRNA expression in the wildtype animals in hippocampus, prefrontal cortex and amygdala 329 (data not shown).

330 
332 In the present study, we characterized for the first time $\mathrm{Morcl}^{-/}$mice in a test battery for 333 emotional behavior. Morcl $^{-/-}$mice floated earlier in the Forced Swim Test and showed more 334 immobility in general. In the Learned Helplessness Paradigm, they exhibited a higher latency 335 to escape and more escape failures, two parameters that are seen as classical indicators for 336 increased learned helplessness in rodents [50]. $\mathrm{MorCl}^{-/}$mice showed a significant increase of 337 immobility in the Forced Swim Test only on day 2 and just as a statistical tendency on day 1. 338 Although day 1 is regarded as more relevant for mice than day 2, the consistently increased 339 means of immobility on both days taken together with the results of the Learned Helplessness 340 Test, allow to postulate a clear increase in depressive-like behavior of $\mathrm{Morcl}^{-/}$mice.

341 Anxiety is often concomitant to depression in psychiatric patients. Up to now, the question if 342 Morcl is also involved in anxiety disorders has not been examined in clinical trials. In our 343 animal model we did not find any evidence of increased anxiety in Morcl $^{-/-}$mice in the Dark344 Light Box Test and Elevated O-Maze, indicating that Morcl may specifically be involved in 345 depression but not anxiety. We were able to exclude reduced locomotion and exploratory 346 behavior as possible confounding factors in our study, as $\mathrm{Morcl}^{-/}$mice did not show any 347 difference to their wild-type littermates in the Novel Cage and Open Field Test.

348 All in all, this new transgenic mutation seems to represent a promising model to further 349 investigate the depressive phenotype and its underlying neurochemical, genetic and epigenetic 350 pathophysiology.

352 Besides a deficient spermatogenesis, small testical size and aberrant eye pigmentation, 353 Watson et al. [22] described no phenotypic abnormalities in male Morcl-mutant mice. In our 354 breeding, we found increased mortality in male $\mathrm{Morcl}^{-/}$mice, and the small sample size of 355 males in our cohort constrained us to focus only on females for our behavioral testing. 356 Although we bred only for two generations, a random effect cannot be definitely dismissed, 
yet this increased mortality might be another confirmation of Morcl - as already stated above

358 - not only being involved in spermatogenesis but serving a more general biological function $359 \quad[31],[32],[33]$.

360 This leads to the more general question why Morcl might be involved in spermatogenesis as

361 well as in mood disorders - two biological processes seemingly independent at first glance.

362 Soumillon et al. [51] come to the conclusion that a considerable part of genes expressed in 363 testes do not have testes-specific functions. Shen et al. [52] could demonstrate that testes364 specific genes usually have a fast evolutionary rate and therefore are more likely to gain new 365 functions. In their phylogenetic analysis they illustrate that some open reading frames were 366 first expressed in testis and later in evolution got expressed in other tissues. The authors 367 assume that testis may play a role in producing new genes and even in supporting testes368 specific genes in gaining new functions for other organs/tissues. Blendy et al. [53] for 369 example demonstrated that the Crem gene is involved in spermatogenesis. Aguado et al. [54]

370 found the same gene being involved in hippocampal synaptogenesis. Wang et al. [55] proved 371 another gene - hsf-2 - to be involved in sperm production as well as central nervous 372 development.

374 As women are more often affected by major depressive disorder than men [56], [57], we saw 375 the restriction to female ${ }^{-/-}$mice in the present study as a possibility for validly modeling 376 depression. Nevertheless, sex differences with respect to the development of depressive-like 377 behaviors in mice with targeted mutagenesis have also been reported for other genes such as 378 BDNF [58], [59], [60]. Therefore another study on male $\mathrm{Morcl}^{-/-}$mice and their conceivable 379 depressive-like behavior seems appealing. A possible sex effect in our animal model could 380 also shed more light on the differing pathophysiology of depression in women and men. 381 Moreover, additional behavioral tests concerning e.g. social behavior and cognition that are 
often correlated to depressive-like behavior, are warranted to further characterize the novel

383 Morcl mouse model of depression.

We did not detect any difference regarding baseline corticosterone levels in $\mathrm{Morcl}^{-/-}$mice suggesting that the HPA-axis in these animals is not disrupted under resting conditions. This

387 does not exclude the possibility that the hormonal responsiveness is affected under 388 challenging conditions.

We also investigated BDNF expression that represents a prototype marker of neuronal 391 plasticity, which has often been associated with a depressive phenotype, its expression being 392 reduced in the brain of depressed subjects as well as in different animal models of depression 393 [61], [62] - summarized in the so-called neurotrophin hypothesis of depression. Contrary to 394 these previously found changes, the hippocampal expression of BDNF was upregulated in $395 \mathrm{Morcl}^{-/}$mice, whereas a trend toward a reduction was found in the prefrontal cortex. Despite 396 the complex interactions between glucocorticoids and BDNF, this finding might be narrowed 397 down to the undisturbed HPA-Axis in our animals, as BDNF is mostly suppressed by 398 glucocorticoids [63], [64].

399 An alternative explanation for this unexpected result may be sex differences. Interestingly, the 400 decrease of BDNF in depressed patients was found to be more pronounced in men than in 401 women [65]. Hayley et al. [66] demonstrated that in female depressed patients who committed 402 suicide BDNF protein levels were reduced in the frontopolar prefrontal cortex, but not in the 403 hippocampus. Conversely, males displayed significantly decreased BDNF protein levels only 404 in the hippocampus yet not in the prefrontal cortex. Jaworska et al. [67] showed a significant 405 decrease of BDNF in the hippocampus of male, but not of female gerbils after early life stress. 406 As we used only female mice for our experiment, this sex-specific regulation could be the 407 reason for the lack of a BDNF down-regulation in our study. Furthermore, there is growing 
evidence that estradiol can induce BDNF expression and vice versa that estradiol effects in

409 the hippocampus are mediated by BDNF [68], [69], [70], [71].

411 In a recent study, Calabrese et al. [72] demonstrated that BDNF in serotonin transporter 412 knock-out rats, which had been exposed to early life stress was down-regulated in the ventral 413 hippocampus and the ventromedial prefrontal cortex, but was significantly increased in the 414 dorsal hippocampus and the dorsomedial prefrontal cortex. A similar region-specific process 415 might underlie the detected increase of BDNF in hippocampus in the present study with the 416 amount of BDNF in the dorsal parts outweighing the downregulation in the ventral parts. We 417 did not differentiate between the dorsal and ventral regions of hippocampus and prefrontal 418 cortex, but this issue would be very interesting to address in future experiments.

However, all these aspects fail to entirely explain the highly significant increase of BDNF we 421 found in hippocampus of $\mathrm{Morcl}^{-/}$mice. In contrast, the trend of reduced BDNF in prefrontal 422 cortex and amygdala of $\mathrm{MorCl}^{-/}$mice is more in line with previous findings showing either 423 no change of BNDF in these two regions [73] or a decrease in depressive-like animals [74] 424 and depressive humans [75].

426 Last, increased BDNF levels in the hippocampus might also be the consequence of 427 compensatory mechanisms set in motion in Morcl mutants. Thus, Faure et al. [76], Marais et 428 al. [77] and Daniels et al. [78] found a significant increase of BDNF in (dorsal) rat 429 hippocampus after maternal separation during early life. Hellweg et al. [79] also found a 430 significant increase of BDNF in bulbectomized depressive-like mice. According to the 431 authors this finding in addition to the fact that bulbectomized animals display different 432 behavioral abnormalities than glucocorticoid receptor compromised mice as well as a 433 serotonergic dysfunction possibly defines a new endophenotype of depression. Although 
434 Morcl $^{-/-}$mice show the same depressive-like phenotype with deficiencies in the FST and LH

435 paradigm as described by the animals used for the neurotrophin hypothesis of depression,

436 their serotonergic function has not been evaluated yet. Maybe Morcl $^{-1-}$ mice constitute an

437 intermediate endophenotype situated between the two previously described animal models.

438 Nonetheless, as BDNF-levels in the brain have never been analyzed before in $\mathrm{Morcl}^{-{ }_{-}}$mice,

439 the regulation of BDNF in regard to Morcl and depression remains a matter of pure 440 speculation. Systematic investigation of this question is required.

442 One of the most intriguing issues to address in the future will be the role of epigenetic 443 modulation by Morcl in the brain. We were the first to detect a different methylation of 444 Morc1 in the prefrontal cortex of the rat brain [20]. In our cross-species and cross-tissues 445 approach, we could prove the particular relevance of Morcl methylation after early life stress. 446 However, to date the specific cerebral subtypes that are affected by Morcl and the concrete 447 epigenetic function of Morcl in the brain is still completely unknown.

448 A further implication of this finding is the question if the methylation pattern will be 449 replicable in the mouse brain or in other regions of the brain like e.g. the hippocampus. As 450 epigenetic processes are always highly sex-specific, it would also be most interesting to examine in which way the epigenetic mark will be expressed differently in male individuals.

453 One limitation of the presented study is certainly that only females have been used so that the 454 model might be a sex-specific. Additionally, as we analyzed BDNF and CORT levels after 455 applying stressful behavioral tests to the animals, we cannot exclude that e.g. the FST or the 456 LH paradigm has had some influence on these parameters. It is thinkable that the increase of $457 \mathrm{BDNF}$ in the hippocampus of $\mathrm{Morcl}^{-/}$mice is due to some compensatory mechanism 458 induced by the higher amount of electric shocks these animals received in the LH paradigm 459 due to their bad performance in this behavioral test. 
460 Our study results are further limited by the fact that we only used Morcl homozygous

461 knockout mice as heterozygous knockouts are usually regarded as a better model for the 462 human condition. We are actually planning to also behaviorally analyze Morcl heterozygous 463 - and male - mice after backcrossing our animals for a few more generations into the c57/b16 464 background.

465

466 In conclusion, although further work still has to be accomplished, the animal model of Morcl $^{-}$ $467{ }^{/}$mice will be useful in future studies on the role of Morcl in the pathophysiology and 468 therapy of depression.

469

4705 Conflict of interest

471 The authors declare no conflict of interest.

472

4736 Acknowledgements

474 This work was supported by an Era-Net Neuron grant to PG, MAR, CF and MD, by grants 475 from the Italian Ministry of University and Research to MAR (PRIN - grant number 476 20107MSMA4_002), from Fondazione CARIPLO to MAR (grant number 2012-0503) and in 477 part by a grant from the Deutsche Forschungsgemeinschaft to PG (SFB636/B3). AL was 478 supported by a Fondazione Umberto Veronesi Fellowship.

479

480 
482 [1] Agid O, Shapira B, Zislin J, Ritsner M, Hanin B, Murad H, et al. Environment and 483 vulnerability to major psychiatric illness: a case control study of early parental loss in major 484 depression, bipolar disorder and schizophrenia. Molecular psychiatry. 1999;4:163-72. [2] Wiersma JE, Hovens JG, van Oppen P, Giltay EJ, van Schaik DJ, Beekman AT, et al. The importance of childhood trauma and childhood life events for chronicity of depression in adults. The Journal of clinical psychiatry. 2009;70:983-9.

[3] Shamseddeen W, Asarnow JR, Clarke G, Vitiello B, Wagner KD, Birmaher B, et al. Impact of physical and sexual abuse on treatment response in the Treatment of Resistant Depression in Adolescent Study (TORDIA). Journal of the American Academy of Child and 491 Adolescent Psychiatry. 2011;50:293-301.

492 [4] Weaver IC, Cervoni N, Champagne FA, D'Alessio AC, Sharma S, Seckl JR, et al. Epigenetic programming by maternal behavior. Nature neuroscience. 2004;7:847-54. [5] Champagne FA, Weaver IC, Diorio J, Dymov S, Szyf M, Meaney MJ. Maternal care associated with methylation of the estrogen receptor-alphalb promoter and estrogen receptoralpha expression in the medial preoptic area of female offspring. Endocrinology. 2006;147:2909-15.

[6] Murgatroyd C, Patchev AV, Wu Y, Micale V, Bockmuhl Y, Fischer D, et al. Dynamic DNA methylation programs persistent adverse effects of early-life stress. Nature neuroscience. 2009;12:1559-66.

[7] Roth TL, Lubin FD, Funk AJ, Sweatt JD. Lasting epigenetic influence of early-life adversity on the BDNF gene. Biological psychiatry. 2009;65:760-9.

[8] Chen J, Evans AN, Liu Y, Honda M, Saavedra JM, Aguilera G. Maternal deprivation in rats is associated with corticotrophin-releasing hormone $(\mathrm{CRH})$ promoter hypomethylation and enhances $\mathrm{CRH}$ transcriptional responses to stress in adulthood. Journal of neuroendocrinology. 2012;24:1055-64.

[9] Jensen Pena C, Monk C, Champagne FA. Epigenetic effects of prenatal stress on 11 betahydroxysteroid dehydrogenase-2 in the placenta and fetal brain. PloS one. 2012;7:e39791. [10] Toledo-Rodriguez M, Lotfipour S, Leonard G, Perron M, Richer L, Veillette S, et al. Maternal smoking during pregnancy is associated with epigenetic modifications of the brainderived neurotrophic factor- 6 exon in adolescent offspring. American journal of medical genetics Part B, Neuropsychiatric genetics : the official publication of the International Society of Psychiatric Genetics. 2010;153b:1350-4.

[11] Vijayendran M, Beach SR, Plume JM, Brody GH, Philibert RA. Effects of genotype and child abuse on DNA methylation and gene expression at the serotonin transporter. Frontiers in psychiatry. 2012;3:55.

[12] Labonte B, Yerko V, Gross J, Mechawar N, Meaney MJ, Szyf M, et al. Differential glucocorticoid receptor exon $1(\mathrm{~B}), 1(\mathrm{C})$, and $1(\mathrm{H})$ expression and methylation in suicide completers with a history of childhood abuse. Biological psychiatry. 2012;72:41-8.

[13] Zorner B, Wolfer DP, Brandis D, Kretz O, Zacher C, Madani R, et al. Forebrain-specific trkB-receptor knockout mice: behaviorally more hyperactive than "depressive". Biological psychiatry. 2003;54:972-82.

[14] Chourbaji S, Hellweg R, Brandis D, Zorner B, Zacher C, Lang UE, et al. Mice with reduced brain-derived neurotrophic factor expression show decreased choline acetyltransferase activity, but regular brain monoamine levels and unaltered emotional behavior. Brain research Molecular brain research. 2004;121:28-36.

[15] Holmes A, Murphy DL, Crawley JN. Abnormal behavioral phenotypes of serotonin transporter knockout mice: parallels with human anxiety and depression. Biological psychiatry. 2003;54:953-9. 

depression-related behaviors and functional changes in the dorsal raphe nucleus of serotonin transporter-deficient mice. Biological psychiatry. 2003;54:960-71. [17] Boyle MP, Kolber BJ, Vogt SK, Wozniak DF, Muglia LJ. Forebrain glucocorticoid receptors modulate anxiety-associated locomotor activation and adrenal responsiveness. The Journal of neuroscience : the official journal of the Society for Neuroscience. 2006;26:1971-8. [18] Labonte B, Suderman M, Maussion G, Navaro L, Yerko V, Mahar I, et al. Genome-wide epigenetic regulation by early-life trauma. Archives of general psychiatry. 2012;69:722-31. [19] Yang BZ, Zhang H, Ge W, Weder N, Douglas-Palumberi H, Perepletchikova F, et al. Child abuse and epigenetic mechanisms of disease risk. American journal of preventive medicine. 2013;44:101-7. [20] Nieratschker V, Massart R, Gilles M, Luoni A, Suderman MJ, Krumm B, et al. MORC1 exhibits cross-species differential methylation in association with early life stress as well as genome-wide association with MDD. Translational psychiatry. 2014;4:e429. [21] Rietschel M, Mattheisen M, Frank J, Treutlein J, Degenhardt F, Breuer R, et al. Genomewide association-, replication-, and neuroimaging study implicates HOMER1 in the etiology of major depression. Biological psychiatry. 2010;68:578-85. [22] Watson ML, Zinn AR, Inoue N, Hess KD, Cobb J, Handel MA, et al. Identification of morc (microrchidia), a mutation that results in arrest of spermatogenesis at an early meiotic stage in the mouse. Proceedings of the National Academy of Sciences of the United States of America. 1998;95:14361-6.

[23] Inoue N, Wei F, Seldin MF, Zinn AR, Watson ML. Assignment of microrchidia (Morc) to mouse chromosome 16 by interspecific backcross linkage analysis and human chromosome 3 q13 using somatic cell hybrids and in situ hybridization. Cytogenetics and cell genetics. 2000;90:123-5.

[24] Pastor WA, Stroud H, Nee K, Liu W, Pezic D, Manakov S, et al. MORC1 represses transposable elements in the mouse male germline. Nature communications. 2014;5:5795.

[25] Condomines M, Hose D, Raynaud P, Hundemer M, De Vos J, Baudard M, et al. Cancer/testis genes in multiple myeloma: expression patterns and prognosis value determined by microarray analysis. Journal of immunology (Baltimore, Md : 1950). 2007;178:3307-15. [26] Shah SP, Morin RD, Khattra J, Prentice L, Pugh T, Burleigh A, et al. Mutational evolution in a lobular breast tumour profiled at single nucleotide resolution. Nature. 2009;461:809-13.

[27] Zheng JS, Arnett DK, Lee YC, Shen J, Parnell LD, Smith CE, et al. Genome-wide contribution of genotype by environment interaction to variation of diabetes-related traits. PloS one. 2013;8:e77442.

[28] Moissiard G, Bischof S, Husmann D, Pastor WA, Hale CJ, Yen L, et al. Transcriptional gene silencing by Arabidopsis microrchidia homologues involves the formation of heteromers. Proceedings of the National Academy of Sciences of the United States of America. 2014;111:7474-9.

[29] Liu ZW, Shao CR, Zhang CJ, Zhou JX, Zhang SW, Li L, et al. The SET domain proteins SUVH2 and SUVH9 are required for Pol V occupancy at RNA-directed DNA methylation loci. PLoS genetics. 2014;10:e1003948.

[30] Langen G, von Einem S, Koch A, Imani J, Pai SB, Manohar M, et al. The compromised recognition of turnip crinkle virus 1 subfamily of microrchidia ATPases regulates disease resistance in barley to biotrophic and necrotrophic pathogens. Plant physiology. 2014; 164:866-78.

[31] Li DQ, Nair SS, Kumar R. The MORC family: new epigenetic regulators of transcription and DNA damage response. Epigenetics : official journal of the DNA Methylation Society. 2013;8:685-93. 
[32] Iyer LM, Abhiman S, Aravind L. MutL homologs in restriction-modification systems and the origin of eukaryotic MORC ATPases. Biology direct. 2008;3:8.

582 [33] Moissiard G, Cokus SJ, Cary J, Feng S, Billi AC, Stroud H, et al. MORC family 583 ATPases required for heterochromatin condensation and gene silencing. Science (New York, 584 NY). 2012;336:1448-51.

585 [34] Perry J, Zhao Y. The CW domain, a structural module shared amongst vertebrates, 586 80 .

[35] Iyer LM, Anantharaman V, Wolf MY, Aravind L. Comparative genomics of transcription factors and chromatin proteins in parasitic protists and other eukaryotes. International journal for parasitology. 2008;38:1-31.

[36] Inoue N, Hess KD, Moreadith RW, Richardson LL, Handel MA, Watson ML, et al. New gene family defined by MORC, a nuclear protein required for mouse spermatogenesis. Human molecular genetics. 1999;8:1201-7.

[37] Duman RS, Monteggia LM. A neurotrophic model for stress-related mood disorders. Biological psychiatry. 2006;59:1116-27.

[38] Sirianni RW, Olausson P, Chiu AS, Taylor JR, Saltzman WM. The behavioral and biochemical effects of BDNF containing polymers implanted in the hippocampus of rats. Brain research. 2010;1321:40-50.

[39] Taliaz D, Loya A, Gersner R, Haramati S, Chen A, Zangen A. Resilience to chronic stress is mediated by hippocampal brain-derived neurotrophic factor. The Journal of neuroscience : the official journal of the Society for Neuroscience. 2011;31:4475-83.

[40] Luoni A, Berry A, Calabrese F, Capoccia S, Bellisario V, Gass P, et al. Delayed BDNF alterations in the prefrontal cortex of rats exposed to prenatal stress: preventive effect of lurasidone treatment during adolescence. European neuropsychopharmacology : the journal of the European College of Neuropsychopharmacology. 2014;24:986-95.

[41] Legge RM, Sendi S, Cole JH, Cohen-Woods S, Costafreda SG, Simmons A, et al. Modulatory effects of brain-derived neurotrophic factor Val66Met polymorphism on prefrontal regions in major depressive disorder. The British journal of psychiatry : the journal of mental science. 2015;206:379-84.

[42] von Bohlen und Halbach O, Zacher C, Gass P, Unsicker K. Age-related alterations in hippocampal spines and deficiencies in spatial memory in mice. Journal of neuroscience research. 2006;83:525-31.

[43] Domanskyi A, Geissler C, Vinnikov IA, Alter H, Schober A, Vogt MA, et al. Pten ablation in adult dopaminergic neurons is neuroprotective in Parkinson's disease models. FASEB journal : official publication of the Federation of American Societies for Experimental Biology. 2011;25:2898-910.

[44] Berkel S, Tang W, Trevino M, Vogt M, Obenhaus HA, Gass P, et al. Inherited and de novo SHANK2 variants associated with autism spectrum disorder impair neuronal morphogenesis and physiology. Human molecular genetics. 2012;21:344-57.

[45] Fuss J, Ben Abdallah NM, Hensley FW, Weber KJ, Hellweg R, Gass P. Deletion of running-induced hippocampal neurogenesis by irradiation prevents development of an anxious phenotype in mice. PloS one. 2010;5.

[46] Weber T, Vogt MA, Gartside SE, Berger SM, Lujan R, Lau T, et al. Adult AMPA GLUA1 receptor subunit loss in 5-HT neurons results in a specific anxiety-phenotype with evidence for dysregulation of 5-HT neuronal activity. Neuropsychopharmacology : official publication of the American College of Neuropsychopharmacology. 2015;40:1471-84.

[47] Chourbaji S, Brandwein C, Vogt MA, Dormann C, Hellweg R, Gass P. Nature vs. nurture: can enrichment rescue the behavioural phenotype of BDNF heterozygous mice? Behavioural brain research. 2008;192:254-8. 

specific ablation of the transcription factor Creb during adulthood induces anxiety but no spatial/contextual learning deficits. Frontiers in behavioral neuroscience. 2014;8:407. [49] Ridder S, Chourbaji S, Hellweg R, Urani A, Zacher C, Schmid W, et al. Mice with genetically altered glucocorticoid receptor expression show altered sensitivity for stressinduced depressive reactions. The Journal of neuroscience : the official journal of the Society for Neuroscience. 2005;25:6243-50.

[50] Chourbaji S, Zacher C, Sanchis-Segura C, Dormann C, Vollmayr B, Gass P. Learned helplessness: validity and reliability of depressive-like states in mice. Brain research Brain research protocols. 2005;16:70-8.

640 [51] Soumillon M, Necsulea A, Weier M, Brawand D, Zhang X, Gu H, et al. Cellular source 641 and mechanisms of high transcriptome complexity in the mammalian testis. Cell reports. $642 \quad 2013 ; 3: 2179-90$.

643 [52] Shen L, Liu G, Zou Y, Zhou Z, Su Z, Gu X. The evolutionary panorama of organspecifically expressed or repressed orthologous genes in nine vertebrate species. PloS one. 2015;10:e0116872.

[53] Blendy JA, Kaestner KH, Weinbauer GF, Nieschlag E, Schutz G. Severe impairment of spermatogenesis in mice lacking the CREM gene. Nature. 1996;380:162-5.

[54] Aguado F, Diaz-Ruiz C, Parlato R, Martinez A, Carmona MA, Bleckmann S, et al. The CREB/CREM transcription factors negatively regulate early synaptogenesis and spontaneous network activity. The Journal of neuroscience : the official journal of the Society for Neuroscience. 2009;29:328-33.

[55] Wang G, Zhang J, Moskophidis D, Mivechi NF. Targeted disruption of the heat shock transcription factor (hsf)-2 gene results in increased embryonic lethality, neuronal defects, and reduced spermatogenesis. Genesis. 2003;36:48-61.

[56] Kornstein SG. Gender differences in depression: implications for treatment. The Journal of clinical psychiatry. 1997;58 Suppl 15:12-8.

[57] Maciejewski PK, Prigerson HG, Mazure CM. Sex differences in event-related risk for major depression. Psychological medicine. 2001;31:593-604.

[58] Urani A, Chourbaji S, Gass P. Mutant mouse models of depression: candidate genes and current mouse lines. Neuroscience and biobehavioral reviews. 2005;29:805-28.

[59] Autry AE, Adachi M, Cheng P, Monteggia LM. Gender-specific impact of brain-derived neurotrophic factor signaling on stress-induced depression-like behavior. Biological psychiatry. 2009;66:84-90.

[60] Monteggia LM, Luikart B, Barrot M, Theobold D, Malkovska I, Nef S, et al. Brainderived neurotrophic factor conditional knockouts show gender differences in depressionrelated behaviors. Biological psychiatry. 2007;61:187-97.

[61] Lindholm JS, Castren E. Mice with altered BDNF signaling as models for mood disorders and antidepressant effects. Frontiers in behavioral neuroscience. 2014;8:143.

[62] Stepanichev M, Dygalo NN, Grigoryan G, Shishkina GT, Gulyaeva N. Rodent models of depression: neurotrophic and neuroinflammatory biomarkers. BioMed research international. 2014;2014:932757.

[63] Vaidya VA, Duman RS. Depresssion--emerging insights from neurobiology. British medical bulletin. 2001;57:61-79.

[64] Shi CG, Wang LM, Wu Y, Wang P, Gan ZJ, Lin K, et al. Intranasal administration of nerve growth factor produces antidepressant-like effects in animals. Neurochemical research. 2010;35:1302-14.

[65] Jiang C, Salton SR. The Role of Neurotrophins in Major Depressive Disorder. Translational neuroscience. 2013;4:46-58. 
[66] Hayley S, Du L, Litteljohn D, Palkovits M, Faludi G, Merali Z, et al. Gender and brain regions specific differences in brain derived neurotrophic factor protein levels of depressed individuals who died through suicide. Neuroscience letters. 2015;600:12-6. [67] Jaworska N, Dwyer SM, Rusak B. Repeated neonatal separation results in different neurochemical and behavioral changes in adult male and female Mongolian gerbils. Pharmacology, biochemistry, and behavior. 2008;88:533-41. [68] Scharfman HE, Maclusky NJ. Similarities between actions of estrogen and BDNF in the hippocampus: coincidence or clue? Trends in neurosciences. 2005;28:79-85.

686

687 [69] Allen AL, McCarson KE. Estrogen increases nociception-evoked brain-derived neurotrophic factor gene expression in the female rat. Neuroendocrinology. 2005;81:193-9.

689 [70] Franklin TB, Perrot-Sinal TS. Sex and ovarian steroids modulate brain-derived neurotrophic factor (BDNF) protein levels in rat hippocampus under stressful and nonstressful conditions. Psychoneuroendocrinology. 2006;31:38-48.

692 [71] Sun MK, Alkon DL. Differential gender-related vulnerability to depression induction and converging antidepressant responses in rats. The Journal of pharmacology and experimental therapeutics. 2006;316:926-32.

[72] Calabrese F, van der Doelen RH, Guidotti G, Racagni G, Kozicz T, Homberg JR, et al. Exposure to early life stress regulates Bdnf expression in SERT mutant rats in an anatomically selective fashion. Journal of neurochemistry. 2015;132:146-54.

[73] Patki G, Solanki N, Atrooz F, Allam F, Salim S. Depression, anxiety-like behavior and memory impairment are associated with increased oxidative stress and inflammation in a rat model of social stress. Brain research. 2013;1539:73-86.

701 [74] Takeda H, Tsuji M, Yamada T, Masuya J, Matsushita K, Tahara M, et al. Caffeic acid attenuates the decrease in cortical BDNF mRNA expression induced by exposure to forced swimming stress in mice. European journal of pharmacology. 2006;534:115-21.

[75] Reinhart V, Bove SE, Volfson D, Lewis DA, Kleiman RJ, Lanz TA. Evaluation of TrkB and BDNF transcripts in prefrontal cortex, hippocampus, and striatum from subjects with schizophrenia, bipolar disorder, and major depressive disorder. Neurobiology of disease. 2015;77:220-7.

[76] Faure J, Uys JD, Marais L, Stein DJ, Daniels WM. Early maternal separation alters the response to traumatization: resulting in increased levels of hippocampal neurotrophic factors. Metabolic brain disease. 2007;22:183-95.

[77] Marais L, van Rensburg SJ, van Zyl JM, Stein DJ, Daniels WM. Maternal separation of rat pups increases the risk of developing depressive-like behavior after subsequent chronic stress by altering corticosterone and neurotrophin levels in the hippocampus. Neuroscience research. 2008;61:106-12.

[78] Daniels WM, Fairbairn LR, van Tilburg G, McEvoy CR, Zigmond MJ, Russell VA, et al. Maternal separation alters nerve growth factor and corticosterone levels but not the DNA methylation status of the exon 1(7) glucocorticoid receptor promoter region. Metabolic brain disease. 2009;24:615-27.

[79] Hellweg R, Zueger M, Fink K, Hortnagl H, Gass P. Olfactory bulbectomy in mice leads to increased BDNF levels and decreased serotonin turnover in depression-related brain areas. Neurobiology of disease. 2007;25:1-7. 